\title{
EFFECTS OF COLOURED LIGHTING ON THE PERCEPTION OF INTERIOR SPACES ${ }^{1,2}$
}

\author{
SEDEN ODABAŞIOĞLU \\ Department of Interior Architecture, Faculty of Fine Arts, Marmara University \\ NILGÜN OLGUNTÜRK \\ Department of Interior Architecture and Environmental Design \\ Faculty of Art, Design and Architecture, Bilkent University
}

Summary.-Use of coloured lighting in interior spaces has become prevalent in recent years. Considerable importance is ascribed to coloured lighting in interior and lighting design. The effects of colour on the perception of interior spaces have been studied as surface colour; but here, the effects of three different types of chromatic light were investigated. The lighting differed in colour (red, green and white) and perceptions of interior space were assessed. 97 participants (59 women, 38 men; $M$ age $=21.4$ yr.) evaluated the experiment room on a questionnaire assessing eight evaluative factors: Pleasantness, Arousal, Aesthetics, Usefulness, Comfort, Spaciousness, Colour, and Lighting quality. Perceptions of the room differed by colour of lighting for some of the evaluative factors, but there was no sex difference in perceptions. Interior spaces may be perceived as equally pleasant under white, green and red lighting. Under white lighting a space is perceived as more useful, spacious, clear, and luminous. Green lighting would make the same effect. Green and white lighting were perceived equally comfortable in an interior space. Chromatic coloured lighting was perceived to be more aesthetic than white lighting. The results support previous findings for some evaluative factors, but differed for others.

Many people spend most of their lives in man-made environments and interact intimately with these spaces. Components of a space are perceived, evaluated, and evoke emotional responses from users (Knez \& Enmarker, 1998; Knez \& Kers, 2000; Manav, 2007b). Natural or artificial light and colour are important physical factors influencing the perception of a space and affect people psychologically (McCloughan, Aspinall, \& Webb, 1999; Knez, 2001; Küller, Ballal, Laike, Mikellide, \& Tonello, 2006).

Flynn and colleagues were pioneers in research on the effects of different properties of white light on users' impressions. They indicated that lighting is a measurable factor affecting impressions of a visual field (Flynn, Spencer, Martyniuk, \& Hendrick, 1973; Flynn \& Spencer, 1977; Flynn, Hendrick, Spencer, \& Martyniuk, 1979). Various studies have been con-

\footnotetext{
${ }^{1}$ Address correspondence to Seden Odabaşioğlu, Department of Interior Architecture, Faculty of Fine Arts, Marmara University, 34660 Kadıköy / İstanbul, Turkey or e-mail (sodabasi@ bilkent.edu.tr).

${ }^{2}$ The authors would like to thank Bilkent University's Interior Architecture and Environmental Design Department for its financial support for the experimental equipment.
} 
ducted, but have been limited to the effects of different properties of light such as correlated colour temperature (the temperature of a blackbody radiator that has a chromaticity equal to the chromaticity of the light source; Boyce \& Cuttle, 1990), spectral power distribution (the relative amount of optical radiation vs wavelength within the visible range; Fotios \& Levermore, 1999), correlated colour temperature and illuminance together (Fleischer, Krueger, \& Schierz, 2001; Manav, 2007a; Oi \& Takashi, 2007, 2009), lighting arrangement (Manav \& Yener, 1999), and illuminance/luminance and lighting arrangement together (Loe, Mansfield, \& Rowlands, 2000; Durak, Olguntürk, Yener, Güvenç, \& Gürçınar, 2007).

In addition to light, effects of surface colour on the perception of interior spaces have also been a subject of research. Countryman and Jang (2006) reported that the three atmospheric elements—colour, light, and style—contributed to the overall impression of a hotel lobby, but colour appeared to be the most influential. Considering the hue dimension of colour, a space is perceived as more spacious with white painted walls than with red or green painted walls (Kwallek, 1996). Lightness of a surface colour also affects perceived spaciousness by influencing the perceived dimensions of an interior space; for instance, Oberfeld and Hecht (2011) found that light ceilings and light walls made an interior space appear higher. However, floor lightness had no significant effect on perceived height (Oberfeld, Hecht, \& Gamer, 2010). According to the results of the study done by Hidayetoğlu, Yildırım, and Akalın (2012) on the hue dimension of colour, a neutral-coloured space was perceived more negatively than other colour schemes (warm and cool) and a warm coloured space was perceived as more attractive than others (neutral and cool). In interior spaces, cool colours (blue or green) are perceived as pleasant, comfortable, calm, and peaceful, while warm colours (red or orange) are perceived as more stimulating; also, the spaces were perceived as smaller with warm colours (Bellizi, Crowley, \& Hasty, 1983; Crowley, 1993; Stone, 2003; Yıldırım, Çapanoğlu, Çağatay, \& Hidayetoğlu, 2012).

Coloured lights influence psychological states. In Laufer, Lang, Izso, and Nemeth (2009), blue light was more activating and red light was more relaxing. Blue light was also rated as more unpleasant than red light. On the other hand, studies considering surface colours indicated that blue was perceived more positively than orange in interiors (Babin, Hardesty, \& Suter, 2003). Stores with cool colours were perceived as more pleasant and attractive than those with warm colours (Bellizzi, et al., 1983). Stone and English (1998) indicated that cool colours are calming and warm colours are activating.

Changes in lifestyles and cultural attitudes affect the design of interior spaces. Today, there is a tendency to use coloured lighting in both interior and exterior spaces. Although there have been different methods for 
using coloured light, as a result of the developments in technology it is easy to apply and obtain. New technologies and changing attitudes have led to increased use of coloured lights in everyday settings.

Coloured lights are increasingly being used in diverse spaces, such as parks, building facades, interiors of bars, restaurants, hotels, houses, cinemas, shops, and even in offices. Therefore, understanding the effects of coloured lighting on space perception is gaining importance. The goal of this study is to assess the perceived appearance and subjective interpretation of a space when coloured lights are used; specifically, whether an interior space would be perceived differently depending on the hue of the surface colours of that space. Perceptions were expected to differ for the various colours. A sex difference in evaluations was also expected, since previous studies found that men and women react differently to colour and light (Knez \& Kers, 2000; Knez, 2001; Yıldırım, Akalın-Başkaya, \& Hidayetoğlu, 2007).

Hypothesis 1. An interior space will be perceived as more pleasant, aesthetic, usable, comfortable, spacious, and to have better lighting quality under one of the chosen colours of lighting: white, red, or green.

Hypothesis 2. The interior space would be perceived as more pleasant, aesthetic, usable, comfortable, spacious, and to have better lighting quality depending on sex.

\section{METHOD}

\section{Participants}

The sample consisted of 97 students ( 59 women, 38 men) from Bilkent University in Ankara, Turkey. To eliminate effects of interpersonal differences in perceptions, the same sample was used under all three experiment lighting conditions. The majority of the participants were from the Department of Interior Architecture and Environmental Design (94\%). The experiment did not test the effects of age. The mean age of the participants was 21.4 yr. (range $=18$ to 31 ), and they were generally in their second year in an undergraduate program.

\section{Experiment Room}

The experiment was conducted in the Building Science Laboratory of the Department of Interior Architecture and Environmental Design. The room had no windows and no heating units. The room measured $4.10 \mathrm{~m} \times 4.18 \mathrm{~m}\left(17.1 \mathrm{~m}^{2}\right.$ total area $)$ and the ceiling height was $3.84 \mathrm{~m}$. The walls and the ceiling were painted in matte white (Munsell N9) and the floor was covered with $30 \times 30 \mathrm{~cm}$ gray (Munsell N5) terrazzo tiles. The 


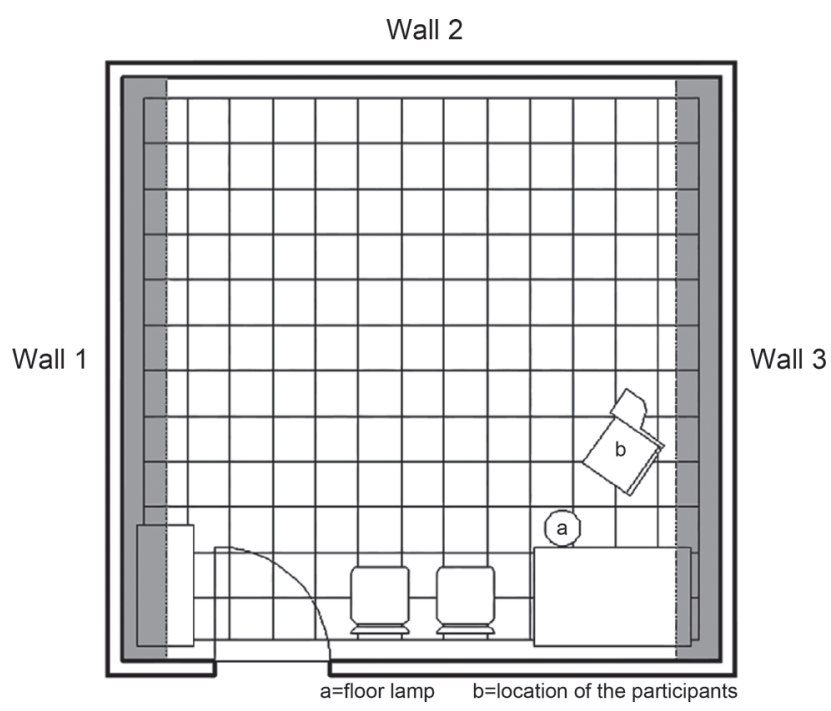

FIG. 1. Plan of the experiment room (position of the fluorescent lamps is shown in gray)

room had three existing lighting types: spotlights, wall wash fixtures to distribute light on the wall, and cove lighting to direct light toward ceilings. Cove lighting and wall wash fixtures were installed on the two facing walls $4.10 \mathrm{~m}$ apart (Fig. 1), $60 \mathrm{~cm}$ below the ceiling, with dimmable electronic ballasts required for dimming the fluorescent lamps. This room was chosen for the experiment because it had no windows and no daylight, so changes in atmosphere related to artificial lighting could be evaluated easily and reliably. The arrangement of the room was changed for the purposes of the study: one chair and one floor lamp (a tall lamp standing on the floor) were used for task lighting in the room, as shown in Fig. 1 and Fig. 2.

Fluorescent lamps with dimmable electronic ballasts were used for the experiment and the walls were washed with red, green, and white lights. Previous studies regarding surface colours used different colours differing in hue: Kwallek (1996) used red, green, and white; Yıldırım, et al. (2007) used yellow and violet; Babin, et al. (2003) used blue and orange; Crowley (1993) used blue, green, yellow, and red; and Stone (2003) used red and blue. This diversity of colours used in previous studies and the limitation of differences in illuminance levels of coloured lights affected the selection of colours for this study. Blue light had lower illuminance than red and could not be equalized with red light, which prevents the selection of colours red and blue. Thus, red and green lights were selected for this study. For the white lighting, six Philips TLD36/54 fluorescent lamps were used, with a colour temperature value of $6200 \mathrm{~K}$ and a colour rendering index of 72 . For the chromatic coloured lighting, six OS- 


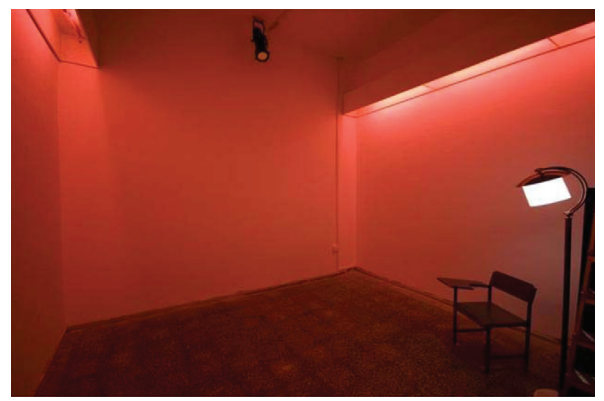

FIG. 2. View of the experiment room showing the fitting elements under the red coloured light

RAM L36W / 60 (red) and six OSRAM L36W / 66 (green) coloured fluorescents were used. In addition to these, an OSRAM DSTAR TW 24W/865 compact fluorescent lamp with a colour temperature value of $6500 \mathrm{~K}$ was installed in the floor lamp for task lighting used simultaneously with all three lighting conditions.

The chromas of the fluorescent lamps used for the wall wash lighting were measured with a Minolta Chroma Meter CS-100, which has a CIE1931 $2^{\circ}$ standard observer spectral response, to obtain their chromaticity coordinates $(\mathrm{red}=\mathrm{Y} \rightarrow 3110, \mathrm{x} \rightarrow 0.595, \mathrm{y} \rightarrow 0.335$, green $=\mathrm{Y} \rightarrow 3130$, $x \rightarrow 0.313, y \rightarrow 0.547$, white $=Y \rightarrow 3140, x \rightarrow 0.328, y \rightarrow 0.348)$. For coloured lighting, coloured fluorescent lamps were chosen because they were economical, easy to install, and dimmed with the existing system in the room. White fluorescent lamps were chosen because they are broadly used; although they have a low CRI, they have a colour temperature value which is close to daylight, thus helping to understand the role of chromatic lighting in perception, and they were used as a control condition.

The illuminance on the surface of the armrest of the chair where the participants filled in the questionnaire was fixed to 323lux for all lighting, which is acceptable for reading tasks (IESNA, 2000). The wall surface luminances of the experiment room were measured with a Minolta LS-100 luminance meter at the center point and $20 \mathrm{~cm}$ away from the corners of the walls. Mean values for each wall were at proximate levels (Table 1). The experiment room is shown in Fig. 3.

\section{Measure}

If people are expected to evaluate an architectural space, they need tools (Kasmar, 1992). A tool can be a scale appropriate for the space, with adjectives that are descriptive of that space. However, as stated in most studies, there is not an available specific source of such items and most researchers use scales they have created themselves. For example, Flynn and 
TABLE 1

Wall Surface Luminances of the Experiment Room (CD/M²)

\begin{tabular}{lccc}
\hline \hline \multicolumn{1}{c}{ Colour } & Wall 1 & Wall 2 & Wall 3 \\
\hline Red & 60.7 & 73.2 & 62.1 \\
Green & 62.3 & 73.5 & 64.0 \\
White & 62.8 & 74.2 & 64.3 \\
\hline
\end{tabular}

his colleagues focused on scaling procedures for studying subjective impressions of lighting in a space and proposed a measurement tool (Flynn, et al., 1973; Flynn \& Spencer, 1977; Flynn, et al., 1979). Some of the studies done on the subjective evaluation of spaces under different lightings were

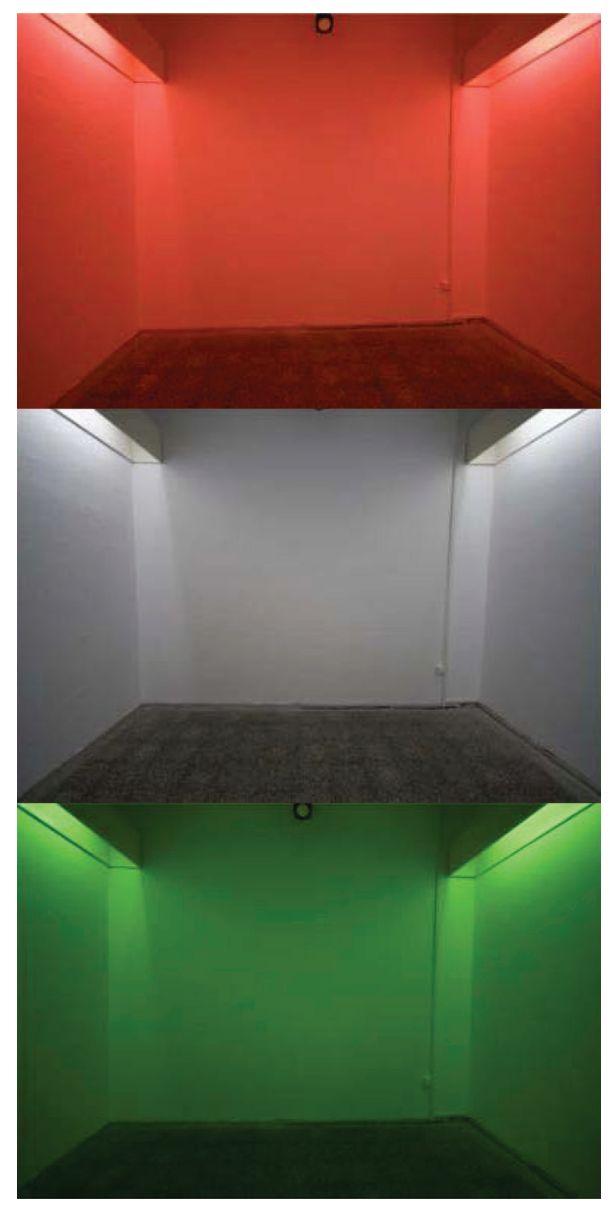

FIG. 3. View of the experiment room with all three lighting colours 
inspired by the studies of Flynn and have developed the scales further (Heerwagen \& Heerwagen, 1986; Mania, 2001; Houser, Tiller, Bernecker, \& Mistrick, 2002). Additionally, considering effects of surface colours, Hogg, Goodman, Porter, Mikellides, and Preddy (1979) used bipolar adjectives from Tucker (as cited in Osgood, 1957) for rating colour samples and a simulated interior, whereas Yildırım, et al. (2007) developed a list of semantic differential items of general attributes for evaluating the perceptual quality of a cafe/ restaurant.

A common psychometric method used in lighting research is semantic differential scaling, developed by Osgood (1957). In order to prepare the questionnaire, firstly, bipolar adjectives from previous studies mentioned above and other studies about lighting, colour, and environmental appraisal (Kasmar, 1992; Gifford, 2002; Gao \& Xin, 2006) were gathered. Adjective pairs not suitable for evaluating an empty room were eliminated. Secondly, the adjective pairs were translated into Turkish with the help of dictionaries (Türkçe'de Anlamdaş ve Karşıt Kelimeler Sözlüğü, 1982; Oxford Turkish Dictionary, 1992; Türkçe'de Yakın ve Karşıt Anlamlılar Sözlüğü, 1998; Redhouse Sözlüğü İngilizce-Türkçe, 2006), and those that were the same or had similar meanings in translation were eliminated. Some adjective pairs were eliminated because their meanings did not apply to the experiment, and some new pairs were added. The adjective pairs that remained after these eliminations and additions were divided into eight scales according to the factors they evaluated (Table 2), and were used in the questionnaire for evaluating the perception of space under different lighting.

The eight scales with adjective pairs, evaluating a specific factor of a space are as follows (see Table 2 for adjective pairs):

Pleasantness.-This is a subjective evaluation of whether or not a space is appealing. An interior space can be perceived as more or less appealing depending on the lighting conditions (Reisinger, Huedo, \& Vogels, 2008). For instance, luminance distributions (Veitch, 2001) and illuminance levels influence the pleasantness of a space (Fleischer, et al., 2001; Manav \& Küçükdoğu, 2006). Pleasantness ratings also vary with the wavelength of the light (Bornstein, 1975). Lewinski (1938) found that blue and green lights were found to be the most pleasant in a room, whereas orange and yellow lights were the most unpleasant. In addition, red light was found to be less pleasant than green and blue lights (Rajae-Joordens, 2011). On the other hand, Walton and Morrison (1931) found that when the intensities of the lights were equal, red light was the most preferred one among blue, green, yellow, and white lights in a space.

Arousal.-This is a subjective evaluation of whether or not a space arouses the emotions of its occupants. Light and colour in a space influence 
TABLE 2

Eight Scales and Adjective Pairs

\begin{tabular}{|c|c|c|c|}
\hline Pleasantness & Arousal & Aesthetics & Usefulness \\
\hline \multicolumn{2}{|c|}{ attractive/unattractive static/dynamic } & beautiful/ugly & private/public \\
\hline $\begin{array}{l}\text { satisfying/unsatis- } \\
\text { fying }\end{array}$ & interesting/boring & clean/dirty & efficient/inefficient \\
\hline like/dislike & cheerful/gloomy & distinctive/ordinary & $\begin{array}{l}\text { convenient/inconve- } \\
\text { nient }\end{array}$ \\
\hline \multirow{2}{*}{$\begin{array}{l}\text { pleasant/unpleasant } \\
\text { impressive/unimpres- } \\
\text { sive }\end{array}$} & calming/exciting & tasteful/tasteless & useful/useless \\
\hline & relaxing/tense & $\begin{array}{l}\text { usual/unusual } \\
\text { stylish/unstylish }\end{array}$ & $\begin{array}{l}\text { functional/non-func- } \\
\text { tional }\end{array}$ \\
\hline Comfort & Spaciousness & Light & Colour \\
\hline \multirow{3}{*}{$\begin{array}{l}\text { comfortable/uncom- } \\
\text { fortable } \\
\text { glaring/non-glaring }\end{array}$} & high/low & bright/dim & light/dark \\
\hline & large/small & clear/hazy & vibrant/dull \\
\hline & spacious/cramped & light/dark & warm/cool \\
\hline $\begin{array}{l}\text { great eye discomfort/ } \\
\text { no eye discomfort }\end{array}$ & wide/narrow & $\begin{array}{l}\text { good lighting/poor } \\
\text { lighting }\end{array}$ & strong/weak \\
\hline
\end{tabular}

how people feel in that space. Nakshian (1964) stated that red surroundings have arousing and exciting effects on behaviour, whereas green was restful and relaxing. Red light was found to be more arousing than green and blue lights (Rajae-Joordens, 2011).

Aesthetics.-This is a subjective evaluation of whether or not a space is beautiful, distinctive, tasteful, and stylish. Light and colour in a space can change its aesthetic evaluation. Veitch (2001) stated that aesthetic judgments are related to the interpretation and categorization of what people see.

Usefulness.-This is a subjective evaluation of whether or not a space is for public or private use, or useful, functional, or efficient. Impressions of privacy change depending on how the space is to be used, according to the Illuminating Engineering Society Lighting Handbook (IES, 1987). Studies regarding the effects of light determined that low lighting was preferred to achieve privacy, whereas high illuminance was preferred for public use (Nakamura \& Karasawa, 1999; Durak, et al., 2007). Surface colour also influenced perceived privacy, which was higher when the environment was red than it was when the environment was blue (Stone, 2003).

Comfort.-This is a subjective evaluation of whether or not a space is comfortable. Comfort regarding lighting in a space is based on the following factors: room size and shape, room surface reflectance, illuminance lev- 
el, lamp type, number and location of lamps, luminance, light distribution, and differences in individual glare sensitivity (IES, 1987). Surface colours also influence perceived comfort. Studies indicated that interior spaces with cool colours, such as blue or green, were perceived as more comfortable than warm colours such as red or orange (Crowley, 1993; Yıldırım, et al., 2012).

Spaciousness.-This is a subjective evaluation of whether or not a space is spacious. Studies indicated a variance in judgments of spaciousness due to the amount of light in a space (Kirschbaum \& Tonello, 1997), and high lighting level was preferred for spaciousness (Stamps, 2007; Durak, et al., 2007). Considering hue dimension of colour, a space is perceived as more spacious with white painted walls than with red or green painted offices (Kwallek, 1996). Yildırım, et al. (2012) supported that interior spaces with warm colours, such as red or orange, were perceived smaller than the spaces with cool colours, such as blue or green. The perception of spaciousness can be increased by using cool, desaturated colours that have high brightness value and decreased by using warm, saturated colours that have low brightness value (Franz, 2006). In this study, colour of light was varied, while lighting was kept identical for all lights.

Lighting quality.-This is a subjective evaluation of whether or not a space is perceived as light, bright, and clear. To obtain clarity in a space, general lighting and wall wash lighting are preferred to cove lighting (Durak, et al., 2007). Bornstein (1975) indicated that lights of equal radiance are perceived to be brightest for wavelengths between $550 \mathrm{~nm}$ and $560 \mathrm{~nm}$, corresponding to yellow-green. The perception of brightness decreases dramatically toward violet and red. This is related to the spectral sensitivity of human vision. Under an equal luminance condition, light of different wavelengths must have equal apparent brightness (Bornstein, 1975). According to Tiller and Veitch (1995), the apparent brightness of a room depends not only on the amount of light falling on the horizontal surfaces in the space but also on light source colour and lamp colour rendering. Colour rendering is the effect of a light source on the colour appearance of objects. Interiors lit by light sources with high colour rendering and colour temperature values are perceived as brighter (Fotios, 2001).

Colour.-Perception of colour of wall surfaces in a space. Yildirım, et al. (2007) found that interiors with violet surfaces were perceived as cooler than interiors with orange surfaces. The hue dimension of colour is considered in this study.

\section{Procedure}

The participants were first tested for their colour vision with Ishihara's tests for colour blindness. According to Ishihara's tests, none of the participants had colour deficiencies. In addition, the participants requiring corrective lenses $(46.4 \%$ ) were asked to wear them for the experiment. 
Only one participant was in the experiment room at a time, entering it from a corridor illuminated with Philips TLD36/54 fluorescent lamps. After an adaptation time to the lighting in the experiment room, each participant evaluated the space under one coloured lighting using a bipolar semantic differential rating scale for each of the adjective pairs presented to them on a paper. The scales were anchored by an adjective on the left and right side of the paper, and between the two adjectives there was a continuous line segmented into five boxes. Participants were instructed to mark the line; the closest box to their mark was the rating assigned: Extremely, Slightly, or Neutral.

\section{Design and Analysis}

The experiment was a multivariate repeated-measures design. The participants all experienced the three different lighting conditions. There was at least one week in between viewing of each lighting set-up.

The Statistical Package for the Social Sciences (SPSS) 20.0 was used to analyze the data collected from the questionnaires. First, the scales were tested using factor analysis. Factor analyses indicated that six of the scales had one dimension. Then the internal consistency reliability of the scales was tested using Cronbach's coefficient $\alpha$, and only the scales that had $\alpha$ over .70 were used in analyses (Table 3). The scales Arousal $(\alpha=.33)$ and Colour $(\alpha=.53)$ were eliminated from the results because of low internal consistency. The corrected item-total correlations were also considered. Kline (1993) stated that the value of corrected item-total correlation should be at least .30. For the Aesthetics scale there was one adjective pair (usual/ unusual), and for the Usefulness scale there was one adjective pair (private/public) with item-total correlations below .30. Therefore, these two adjectives were eliminated.

The independent variables of the study were the three lights differing in hue (red, green, white) and sex (women, men). Colours of light were entered as within-subjects factors and sex was entered as a between-subjects factor. The dependent variables were the six evaluative factors (Pleasantness, Aesthetics, Comfort, Usefulness, Spaciousness, and Lighting quality). Since there were multiple variables, for testing the hypotheses the data (average ratings of all the adjective pairs of each scale) were first analyzed with a doubly multivariate repeated-measures analysis of variance (ANOVA). Considering the results, univariate repeated-measures ANOVAs were conducted for further analysis of the six factors using a Bonferroni adjustment.

\section{RESULTS}

The results of the multivariate repeated-measures ANOVA indicated that lighting colour had a significant effect on the perception of space re- 
TABLE 3

Evaluative Factors, Adjective Pairs, and Mean Results of the Adjective Pairs

\begin{tabular}{|c|c|c|c|c|c|c|c|c|}
\hline \multirow{2}{*}{ Scale and Adjective Pair } & \multicolumn{2}{|c|}{ Red } & \multicolumn{2}{|c|}{ Green } & \multicolumn{2}{|c|}{ White } & \multirow{2}{*}{$\begin{array}{l}\text { Item } \\
\text { Reli- } \\
\text { ability }\end{array}$} & \multirow{2}{*}{$\begin{array}{l}\text { Scale Re- } \\
\text { liability }\end{array}$} \\
\hline & $M$ & $S D$ & $M$ & $S D$ & $M$ & $S D$ & & \\
\hline $\begin{array}{l}\text { Pleasantness } \\
\text { Attractive/unattractive }\end{array}$ & 3.35 & 1.19 & 3.31 & 1.16 & 3.10 & 1.00 & .80 & .92 \\
\hline Satisfying/unsatisfying & 3.15 & 1.13 & 3.19 & 1.17 & 3.30 & 1.17 & .79 & \\
\hline Like/dislike & 3.33 & 1.21 & 3.38 & 1.25 & 3.26 & 1.12 & .86 & \\
\hline Pleasant/unpleasant & 3.37 & 1.24 & 3.34 & 1.29 & 3.25 & 1.17 & .84 & \\
\hline Impressive/unimpressive & 3.20 & 1.20 & 3.01 & 1.19 & 2.32 & 1.12 & .69 & \\
\hline \multicolumn{9}{|l|}{ Aesthetics } \\
\hline Beautiful/ugly & 3.34 & 1.24 & 3.40 & 1.12 & 3.35 & 1.07 & .72 & .78 \\
\hline Clean/dirty & 3.40 & 1.02 & 4.04 & .97 & 4.40 & .77 & .49 & \\
\hline Distinctive/ordinary & 3.78 & 1.07 & 3.55 & 1.15 & 1.71 & .91 & .31 & \\
\hline Tasteful/tasteless & 3.30 & 1.17 & 3.26 & 1.06 & 2.66 & 1.05 & .73 & \\
\hline Stylish/unstylish & 3.07 & 1.16 & 2.85 & 1.20 & 2.96 & 1.19 & .63 & \\
\hline \multicolumn{9}{|l|}{ Usefulness } \\
\hline Efficient/inefficient & 2.69 & 1.01 & 3.20 & 1.06 & 4.12 & 1.00 & .70 & .88 \\
\hline Convenient/inconvenient & 2.72 & 1.12 & 3.01 & 1.09 & 4.11 & .93 & .82 & \\
\hline Useful/useless & 3.05 & 1.04 & 3.34 & 1.04 & 4.15 & .88 & .82 & \\
\hline Functional/non-functional & 2.99 & 1.14 & 3.21 & 1.10 & 3.99 & .92 & .68 & \\
\hline \multicolumn{9}{|c|}{ Comfort } \\
\hline Comfortable/uncomfortable & 3.15 & 1.21 & 3.57 & 1.27 & 3.95 & 1.15 & .44 & .76 \\
\hline Glaring/non-glaring & 3.69 & 1.39 & 4.00 & 1.14 & 4.08 & 1.14 & .59 & \\
\hline $\begin{array}{l}\text { Great eye discomfort/no } \\
\text { eye discomfort }\end{array}$ & 3.49 & 1.39 & 3.92 & 1.24 & 4.14 & 1.17 & .75 & \\
\hline \multicolumn{9}{|l|}{ Spaciousness } \\
\hline High/low & 3.12 & 1.20 & 3.81 & 1.12 & 4.11 & .94 & .67 & .87 \\
\hline Large/small & 3.08 & 1.10 & 3.74 & .99 & 4.11 & .94 & .76 & \\
\hline Spacious/cramped & 3.28 & 1.06 & 3.99 & .87 & 4.29 & .76 & .77 & \\
\hline Wide/narrow & 3.20 & .99 & 3.88 & .87 & 4.21 & .90 & .72 & \\
\hline \multicolumn{9}{|l|}{ Lighting quality } \\
\hline Bright/dim & 3.01 & 1.11 & 3.20 & .96 & 3.73 & .94 & .48 & .76 \\
\hline Clear/hazy & 3.04 & 1.22 & 3.49 & 1.12 & 4.28 & .80 & .58 & \\
\hline Light/dark & 3.30 & .91 & 3.78 & .91 & 4.52 & .61 & .66 & \\
\hline $\begin{array}{l}\text { Good lighting/poor } \\
\text { lighting }\end{array}$ & 3.18 & 1.03 & 3.60 & .95 & 4.11 & .90 & .55 & \\
\hline
\end{tabular}


garding the six evaluative factors $\left(F_{12,84}=42.74, p<.001\right.$, partial $\left.\eta^{2}=0.86\right)$. However, there was no significant sex effect $\left(F_{6,90}=0.68, p=.67\right.$, partial $\left.\eta^{2}=0.04\right)$ nor colour $\times$ sex interaction $\left(F_{12,84}=0.83, p=.62\right.$, partial $\left.\eta^{2}=0.11\right)$. Considering the results, separate one-way repeated-measures ANOVAs were conducted for the three lighting colours on the six evaluative factors, but further analysis was not conducted for sex differences.

\section{Evaluative Factors}

The mean ratings for pleasantness were approximately the same for all the lighting colours (Table 2 and Fig. 4). The effect of lighting colour on the Pleasantness ratings was not significant $\left(F_{2,190}=1.34, p=.26\right.$, partial $\eta^{2}=0.01$.

The mean ratings for Aesthetics were similar for red and green, and lower for white lighting (Table 2 and Fig. 3). The effect of lighting colour on the Aesthetics ratings was not significant $\left(F_{2,190}=7.87, p<.001\right.$, partial $\eta^{2}=0.08$ ). Pairwise comparisons of the means of three lighting colours using a Bonferroni adjustment indicated that white lighting was significantly different from chromatic coloured lighting (red and green).

The mean rating for Usefulness for white lighting was higher than for green lighting, which was in turn higher than for red lighting (Table 2 and Fig. 4). The effect of lighting colour on the Usefulness ratings was significant $\left(F_{2,190}=152.04, p<.001\right.$, partial $\left.\eta^{2}=0.62\right)$. Pairwise comparisons of the means of three lighting colours using a Bonferroni adjustment indicated that there were significant differences among all the lighting colours.

The mean ratings for Comfort were similar for white and green, and lower for red lighting (Table 2 and Fig. 4). The effect of lighting colour on Comfort ratings was significant $\left(F_{2,190}=9.94, p<.001\right.$, partial $\left.\eta^{2}=0.10\right)$. Pairwise comparisons of the means of three lighting colours using a Bonferroni adjustment indicated that red lighting was significantly different from white and green lighting.

The mean rating for Spaciousness for white lighting was higher than that for green lighting, which was in turn higher than that for red lighting (Table 2 and Fig. 4). The effect of lighting colour on Spaciousness ratings was significant $\left(F_{2,190}=37.13, p<.001\right.$, partial $\left.\eta^{2}=0.28\right)$. Pairwise comparisons of the means of three lighting colours using a Bonferroni adjustment indicated that there were significant differences among all the lighting colours.

The adjective pairs in the scale "Lighting quality" were bright vs dim, clear vs hazy, light vs dark, and good lighting vs poor lighting. The mean rating for Lighting quality for the white lighting was higher than for the green lighting, which in turn was higher than for the red lighting (Table 2 and Fig. 4). The effect of lighting colour on the Lighting quality ratings 


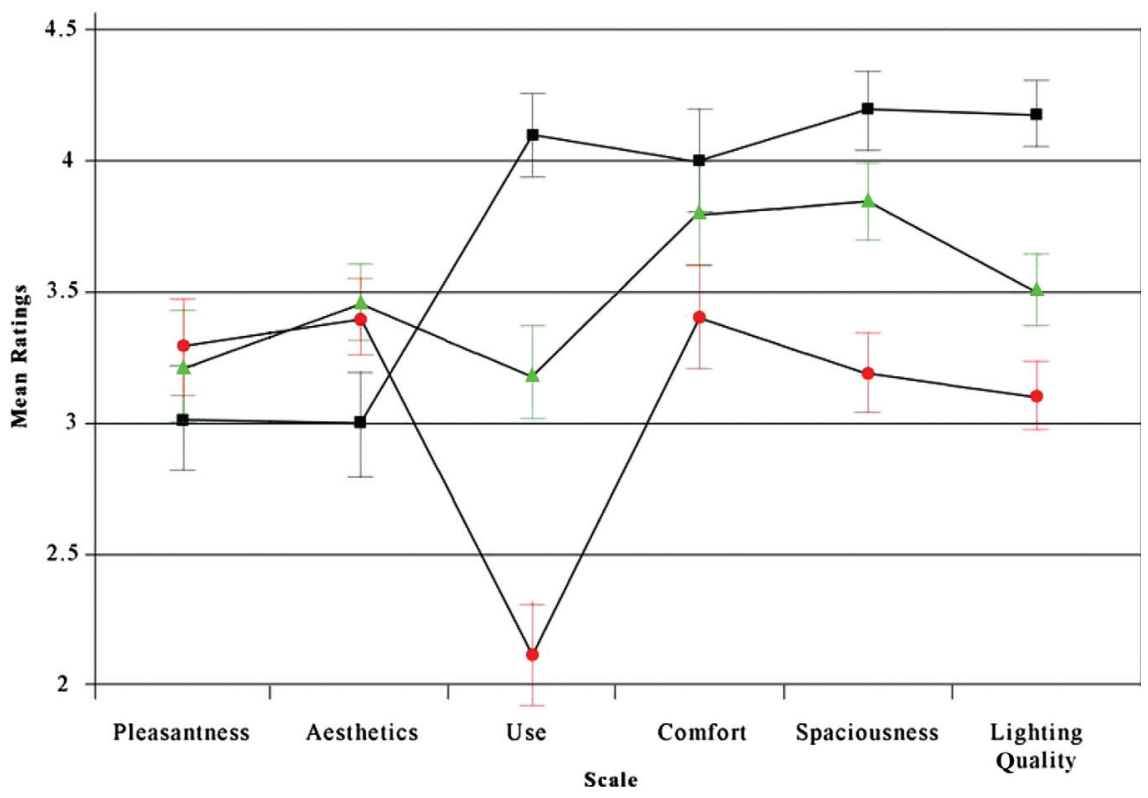

FIG. 4. Mean values of the responses to the scales (means ranged from 1 to 5 , with lower numbers representing negative responses. Error bars represent the $95 \%$ confidence intervals for the standard error of the mean). Ratings are from the red lighting condition (circles), the green lighting condition (triangles), and the white lighting condition (squares).

was significant $\left(F_{2,190}=54.50, p<.001\right.$, partial $\left.\eta^{2}=0.37\right)$. Pairwise comparisons of the means of three lights using a Bonferroni adjustment indicated that there were significant differences among all the lighting colours.

\section{DisCUSSION}

In this study, the effects of coloured lighting on the perception of interior spaces and the difference between chromatic coloured lights and white light in perceptions of the space were explored in an experiment room.

Hypothesis 1. Hypothesis 1 was supported, as the room was perceived as being significantly more pleasant, aesthetic, usable, comfortable, spacious, and to have better lighting quality depending on the colour of the lighting: white, red, or green.

Significant differences were found between red, green, and white lighting in terms of participants' ratings of Aesthetics, Comfort, Lighting quality, Spaciousness, and Usefulness. However, no significant differences on Pleasantness ratings were found between three lighting colours. In the 
literature, the studies regarding light, colour, and space perceptions focus on the effects of surface colour and white light and its properties, such as colour temperature and luminance. It is difficult to compare the results of this study with the results in the literature, since use of chromatic coloured light in a space is not equivalent to applying paint to surfaces. In the former situation, chromatic coloured lights render all the surfaces in a space and they are perceived as if they are seen behind a coloured filter, whereas with paint, although there are reflections that may change the appearance of colours, surface colours are perceived more accurately (depending on the CRI value of the light source) than they are perceived under chromatic coloured lights. The human eye is sensitive to the difference between light colour and surface colour differentiating between coloured objects and coloured light on objects. The use of coloured light on surfaces and its affect on perceptions is the main contribution of this study to the literature. Although direct comparisons with the literature using painted surfaces may not be possible, it is still quite interesting to see the similarities and differences in perceptions.

In the current study, under red lighting the space was perceived to be least comfortable and least spacious, whereas it was perceived as most spacious under white and more comfortable under white and green lighting. Similarly, Manav (2007a) found that under higher colour temperatures, when the colour of the lamp became whiter or bluish white, the space was found more comfortable and more spacious. When considering the effect of surface colour on perception in the literature, it was found that cool colours made a room seem more spacious, whereas warm colours made a room seem smaller and lower (Franz, 2006; Yıldırım, et al., 2007). Kwallek (1996) also stated that white painted offices were perceived as more spacious than red and green painted offices. It is also indicated that interior spaces with cool colours, such as blue or green, were perceived as more comfortable than those painted with warm colours, such as red or orange (Crowley, 1993; Yıldırım, et al., 2012).

Considering the Usefulness scale, it was found that the space was perceived to be more useful under white lighting than it was under others. This might be because white lighting is the most widely used light source. The reason for perceiving the space as more efficient, convenient, useful, and functional under white lighting than under other colours of lighting might also be that mean ratings of Comfort, Spaciousness, and Lighting quality were higher for white lighting than for chromatic coloured lighting. This relation was also supported by mean ratings under the chromatic lighting. Red lighting had the lowest mean ratings for Comfort, Spaciousness, and Lighting quality; accordingly, the space was perceived to be least useful under this lighting. 
As stated above, the results related to the Lighting quality of the space showed that white lighting made the space seem brighter, clearer, and lighter compared to green lighting, and under green than red lighting. Since the three lighting conditions were kept approximately identical in an equal luminance condition, light of different wavelengths had equal apparent brightness (Bornstein, 1975). These results may be related to the colour rendering of the lamps. As Fotios (2001) stated, interiors lit by light sources with high colour rendering and colour temperature are perceived as brighter, and in this study the colour rendering of the white fluorescent lamp was naturally higher than for the red and green fluorescent lamps.

The room was rated as equally Pleasant under all types of lighting. Lewinski (1938), examining people's reactions to different chromatic illuminations in a room, reported blue and green lighting were rated as most pleasant, whereas orange and yellow lights were the most unpleasant in a room and red light was rated between these colours. In addition, red light was found to be less pleasant than green and blue lights (Rajae-Joordens, 2011). On the other hand, Walton and Morrison (1931) found that when the intensities of the lights were equal, red light was the most preferred, above blue, green, yellow, and white lights. Laufer, et al. (2009) also reported that red light was more pleasant than blue light.

Considering the effects of surface colour, Hidayetoğlu, et al. (2012) stated that a neutral-colour space is perceived more negatively than other colour schemes (warm and cool) and warm colour space is perceived more attractive than others (neutral and cool). In interior spaces, cool colours (blue or green) are perceived as more pleasant than warm colours (red or orange) (Bellizi, et al., 1983; Crowley, 1993; Stone, 2003; Y1ldırım, et al., 2012). The findings on the Pleasantness scale varied in the literature, some indicating cool colours in a space were perceived as more pleasant and some indicating the opposite; however, in this study all the coloured lighting was perceived as equally pleasant whereas on the Aesthetics scale chromatic coloured lighting (red and green) were perceived as more aesthetic than white (neutral) lighting. The Aesthetics scale is the only scale that the chromatic coloured lighting was perceived more positively than white (neutral) lighting. The reason for this is that red lighting was referred to as beautiful, distinctive, and tasteful and green lighting was referred to as beautiful, clean, and distinctive, all positive associations with aesthetics. White lighting, on the other hand, had only one positive association as being clean, but being ordinary was found not aesthetic.

Hypothesis 2. The experiment room was perceived as being significantly more pleasant, aesthetic, usable, comfortable, spacious, and to have better lighting quality by both men and women, 
although a sex difference in the evaluations was expected. Sex had no significant effect on ratings of each adjective pair. This finding differed from Yildırım, et al. (2007), since their results indicated that men had a more positive perception of the space than women: women rated the coloured spaces lower than did men.

\section{Conclusion}

The results of this study can be useful for interior architects, designers, and those who use light to create different atmospheres in a space. It is important for designers to understand light and lighting in a space so that they may use it effectively. The results also may assist researchers who study the effects of colour and light on human psychology and perception.

Lighting is a powerful tool in interiors and can change the percept of users. There is no one light or one type of lighting that is "best." Different design intentions or spatial requirements call for different light qualities and lighting techniques. Chromatic coloured lights also were shown to affect perceptions of usefulness in this study.

In future studies, experiments could be conducted in real or virtual spaces that have specific functions. Additionally, the effects of coloured lights different than the ones used in this study can be investigated. A possible age effect on perceptions of different coloured lights may also be investigated.

\section{REFERENCES}

Babin, B. J., Hardesty, D. M., \& Suter, T. A. (2003) Color and shopping intentions: the intervening effect of price fairness and perceived affect. Journal of Business Research, 56, 541-551.

Bellizzi, J. A., Crowley, A. E., \& Hasty, R. W. (1983) The effects of color in store design. Journal of Retailing, 59, 21-45.

BornsteIn, M. H. (1975) On light and the aesthetics of color: lumia kinetic art. Leonardo, 8, 203-212.

Boyce, P. R., \& Cuttle, C. (1990) Effect of correlated colour temperature on the perception of interiors and colour discrimination performance. Lighting Research and Technology, 22, 19-36.

Countryman, C. C., \& JANG, S. (2006) The effects of atmospheric elements on customer impression: the case of hotel lobbies. International Journal of Contemporary Hospitality Management, 18, 534-545.

Crowley, A. E. (1993) The two-dimensional impact of color on shopping. Marketing Letters, 4, 59-69.

Durak, A., Olguntürk, N. C., Yener, C., Güvenç, D., \& Gürçınar, Y. (2007) Impact of lighting arrangements and illuminances on different impressions of a room. Building and Environment, 42, 3476-3482.

Fleischer, S., Krueger, H., \& SChierz, C. (2001) Effect of brightness distribution and light colours on office staff: results of the 'lighting harmony' project. Proceedings of the 9th European Lighting Conference "Lux Europa 2001," Reykjavik, Iceland, June 18-20. Pp. 77-80. 
Flynn, J. E., Hendrick, C., Spencer, T. J., \& Martyniuk, O. (1979) A guide to methodology procedures for measuring subjective impressions in lighting. Journal of the Illuminating Engineering Society, 8, 95-110.

FLynN, J. E., \& SPENCER, T. J. (1977) The effects of light source color on user impression and satisfaction. Journal of the Illuminating Engineering Society, 6, 167-179.

FlynN, J. E., Spencer, T. J., Martyniuk, O., \& Hendrick, C. (1973) Interim study of procedures for investigating the effect of light on impression and behaviour. Journal of the Illuminating Engineering Society, 3, 87-94.

Foтіos, S. A. (2001) Lamp colour properties and apparent brightness: a review. Lighting Research and Technology, 33, 163-181.

Fotios, S. A., \& Levermore, G. J. (1999) The effect of lamp colour properties upon perception: a summary of research and the implications for lighting design. Paper presented at the CIE Symposium '99: 75 years of CIE photometry, Budapest, Hungary, September 30-October 2.

FrANZ, G. (2006) Space, colour, and perceived qualities of indoor environments. Proceedings of the 19th International Association for People-Environment Studies Conference, Alexandria, Egypt, September 11-16. Pp. 1-8.

GAO, X., \& XIN, J. H. (2006) Investigation of human's emotional responses on colors. Color Research and Application, 31, 411-417.

GIFFORD, R. (2002) Environmental psychology: principles and practice. Victoria, British Columbia: Optimal Books.

Heerwagen, J. H., \& Heerwagen, D. R. (1986) Lighting and psychological comfort. Lighting Design and Application, 16, 47-51.

Hidayetoğlu, M. L., Yildirim, K., \& Akalin, A. (2012) The effects of color and light on indoor wayfinding and the evaluation of the perceived environment. Journal of Environmental Psychology, 31, 50-58.

Hogg, J., Goodman, S., Porter, T., Mikellides, B., \& Preddy, D. E. (1979) Dimensions and determinants of judgments of colour samples and a simulated interior space by architects and non-architects. British Journal of Psychology, 70, 231-242.

Houser, K. W., Tiller, D. K., Bernecker, C. A., \& Mistrick, R. G. (2002) The subjective response to linear fluorescent direct/indirect lighting systems. Lighting Research and Technology, 34, 243-264.

ILLUMINATING ENGINEERING SOCIETY (IES). (1987) IES lighting handbook: application volume. New York: Author.

Illuminating Engineering Society of North America (IESNA). (2000) IESNA lighting handbook: reference and application. New York: Author.

Kasmar, J. V. (1992) The development of a usable lexicon of environmental descriptors. In J. Nasar (Ed.), Environmental aesthetics theory, research \& application. Cambridge, UK: Cambridge Univer. Press. Pp. 144-155.

Kirschbaum, C. F., \& Tonello, G. (1997) Visual appearance of office light. Right Light, 1, 143-148.

KLINE, P. (1993) The handbook of psychological testing. London, UK: Routledge.

KNEZ, I. (2001) Effects of colour of light on nonvisual psychological processes. Journal of Environmental Psychology, 21, 201-208.

KNEZ, I., \& ENMARKER, I. (1998) Effects of office lighting on mood and cognitive performance and a gender effect in work-related judgment. Environment $\mathcal{E}$ Behavior, 4, 553-567. 
KNEZ, I., \& KERS, C. (2000) Effects of indoor lighting, gender, and age on mood and cognitive performance. Environment \& Behavior, 6, 817-831.

Küller, R., Ballal, S., Laike, T., Mikellides, B., \& Tonello, G. (2006) The impact of light and colour on psychological mood: a cross-cultural study of indoor work environments. Ergonomics, 49, 1496-1507.

KWALLEK, N. (1996) Office wall color: an assessment of spaciousness and preference. Perceptual \& Motor Skills, 83, 49-50.

LAUfer, L., LANG, E., Izso, L., \& NEMETH, E. (2009) Psychophysiological effects of coloured lighting on older adults. Lighting Research and Technology, 41, 371-378.

LEWINSKI, R. J. (1938) An investigation of individual responses to chromatic illumination. Journal of Psychology, 6, 155-160.

Loe, D. L., Mansfield, K. P., \& Rowlands, E. (2000) A step in quantifying the appearance of a lit scene. Lighting Research and Technology, 32, 213-222.

ManAV, B. (2007a) An experimental study on the appraisal of the visual environment at offices in relation to colour temperature and illuminance. Building and Environment, 42, 979-983.

ManAV, B. (2007b) Color-emotion associations and color preferences: a case study for residences. Color Research and Application, 32, 144-150.

MANAV, B., \& KÜÇÜKDOĞU, M. Ş. (2006) Aydınlık düzeyi ve renk sıcaklığının performansa etkisi [Effects of illumination level and color temperature on performance]. İtü Dergisi [ITU Journal], 5(2), 3-10.

MAnAV, B., \& Yener, C. (1999) Effects of different lighting arrangements on space perception. Architectural Science Review, 42, 43-47.

Mania, K. (2001) Connections between lighting impressions and presence in real and virtual environments: an experimental study. Proceedings of the 1st International Conference on Computer Graphics, Virtual Reality, Visualisation, and Interaction in Africa, Camps Bay, Cape Town, South Africa, November 5-7.

McCloughan, C. L. B., Aspinall, P. A., \& WebB, R. S. (1999) The impact of lighting on mood. Lighting Research and Technology, 31, 81-88.

NAKAMURA, H., \& Karasawa, Y. (1999) Relationship between illuminance/color temperature and preference of atmosphere. Journal of Light and Visual Environment, 23, 29-38.

NAKSHIAN, J. S. (1964) The effects of red and green surroundings on behavior. Journal of General Psychology, 70, 143-161.

Oberfeld, D., \& Hecht, H. (2011) Fashion versus perception: the impact of surface lightness on the perceived dimensions of interior space. Human Factors, 53, 284-298.

Oberfeld, D., Hecht, H., \& Gamer, M. (2010) Surface lightness influences of perceived room height. The Quarterly Journal of Experimental Psychology, 63, 1999-2011.

OI, N., \& TAKAHASHI, H. (2007) Preferred combinations between illuminance and color temperature in several settings for daily living activities. Proceedings of the 26th Session of the CIE (International Commission on Illumination), Vol. 2, Beijing, China, July 4-11. Pp. 173-178.

OI, N., \& TAKAHASHI, H. (2009) A comparison between fluorescent lamp and LED on the preference of indoor illuminance and color temperature. Proceedings of the 6th Lux Pacifica, Bangkok, Thailand, April 23-25. Pp. 123-126.

Osgood, C. E. (1957) The measurement of meaning. Urbana, IL: Univer. of Illinois Press. 
OxFord Turkish Dictionary. (1992) Oxford, UK: Oxford Univer. Press.

RAJAe-Joordens, R. J. E. (2011) The effects of colored light on valence and arousal. In J. Westerink, M. Krans, \& M. Ouwerkerk (Eds.), Sensing emotions: the impact of context on experience measurements. Dordrecht, The Netherlands: Springer Netherlands. Pp. 65-84.

RedHouse SöZlÜĞÜ İNGILIZCE-TÜrKÇe [RedHouse Dictionary English-TurKish]. (2006) İstanbul, Turkey: Sev.

Reisinger, M., Huedo, A., \& Vogels, I. M. (2008) The powers of attraction of chromatic light. Paper No. .084 presented at the Interim Meeting of the International Colour Association, Stockholm, Sweden, June 15-18.

STAMPS, A. E. (2007) Evaluating spaciousness in static and dynamic media. Design Studies, 28, 535-557.

Stone, N. J. (2003) Environmental view and color for a simulated telemarketing task. Journal of Environmental Psychology, 23, 63-78.

Stone, N. J., \& English, A. J. (1998) Task type, posters, and workspace color on mood, satisfaction, and performance. Journal of Environmental Psychology, 18, 175-185.

TilleR, D. K., \& Veitch, J. A. (1995) Perceived room brightness: pilot study on the effect of luminance distribution. Lighting Research and Technology, 27, 93-101.

Türkçe'de Anlamdaş ve Karșit Kelimeler SÖZlüĞü [Dictionary of Synonymous and AntONYMOUS WORDS IN TURKISH ]. (1982) İstanbul, Turkey: İnkılap ve Aka.

TÜrKçE'de Yakin ve Karşit Anlamlilar SÖZlüĞÜ [Synonyms and Antonyms Dictionary in TuRKISH]. (1998) Ankara, Turkey: İmge Kitabevi.

Verтch, J. A. (2001) Psychological processes influencing lighting quality. Journal of the Illuminating Engineering Society, 30, 124-140.

WALton, W. E., \& Morrison, B. M. (1931) A preliminary study of the affective values of colored lights. Applied Psychology, 15, 294-303.

Yildirim, K., AKalin-BaşKaya, A., \& HidayetoĞlu, M. L. (2007) Effects of indoor color on mood and cognitive performance. Building and Environment, 42, 3233-3240.

Yildirim, K., ÇapanoĞlu, A., ÇaĞatay, K., \& HidayetoĞlu, M. L. (2012) Effect of wall colour on the perception of hairdressing salons. Journal of the International Colour Association, 7, 51-63.

Accepted November 13, 2014. 